\title{
Anti-tuberculosis drug resistance and associated risk factors in a tertiary level TB centre in Iran: a retrospective analysis
}

\author{
Muayad A. Merza ${ }^{1,2}$, Parissa Farnia ${ }^{1}$, Payam Tabarsi ${ }^{1}$, Mehdi Khazampour ${ }^{1}$, Mohammad Reza Masjedi ${ }^{1}$, \\ Ali Akbar Velayati ${ }^{1}$ \\ ${ }^{1}$ Mycobacteriology Research Center (MRC), National Research Institute of Tuberculosis and Lung Diseases \\ (NRITLD), Masih Daneshvari Hospital, Shahid Beheshti University of Medical Sciences, Darabad, Tehran, Iran \\ ${ }^{2}$ Azadi Teaching Hospital, College of Medicine University of Dohuk, Dohuk, Kurdistan, Iraq
}

\begin{abstract}
Introduction: This study aimed to determine first-line anti-tuberculosis drug resistance rates in new and previously treated cases and to identify risk factors associated with multidrug resistant tuberculosis (MDR-TB) at the National Reference Tuberculosis Laboratory of Iran. Methodology: This was a retrospective analysis of all confirmed TB patients from December 2000 to June 2005. Drug susceptibility testing to isoniazid, rifampicin, streptomycin, ethambutol and pyrazinamide was performed on Löwenstein-Jensen (LJ) medium according to the proportion method.

Results: Mycobacterium tuberculosis strains were isolated from 1,742 patients with TB, of whom 935 (53.7\%) were male. The mean age of patients was $44.2 \pm 17.4$ years (SD). A total of 1,074 patients were native Iranians while $668(38.3 \%)$ were immigrant patients. Out of 1,139 (65.4\%) new cases, $340(29.9 \%)$ had at least one drug resistance. Of $603(34.6 \%)$ previously treated cases, $416(69.0 \%)$ had resistant strains. There were 263 patients (15.1\%) with MDR-TB, 72 of whom were new (6.3\% of all new cases) and 191 were previously treated (31.7\% of all previously treated cases). Factors associated with MDR-TB included age under 45 years, male sex, previous TB treatment, immigration, poor living conditions, and unemployment.

Conclusions: The high rate of initial resistance in MDR-TB cases and the high rate of MDR-TB in a young age group were indicators of recent transmission. Therefore, closer monitoring of transmission trends of drug resistant strains should be considered as priority, to ensure a successful TB control programme.
\end{abstract}

Key words: Mycobacterium tuberculosis; Iran; multidrug resistant tuberculosis; risk factor

J Infect Dev Ctries 2011; 5(7):511-519.

(Received 04 June 2010 - Accepted 18 November 2010)

Copyright (c) 2011 Merza et al. This is an open-access article distributed under the Creative Commons Attribution License, which permits unrestricted use, distribution, and reproduction in any medium, provided the original work is properly cited.

\section{Introduction}

Tuberculosis (TB) is becoming a worldwide problem due to the recurrence of the disease, the appearance of drug resistant strains, and the association of TB with the HIV pandemic [1]. The emergence of multidrug resistant TB (MDR-TB), i.e. Mycobacterium tuberculosis strains, resistant to at least isoniazid (INH) and rifampicin (RMP), is of great concern, because it requires the use of second-line drugs that are difficult to procure and are much more toxic and expensive than the first-line regimen [2]. Hence the detection and treatment of drug susceptible or single drug resistant $\mathrm{TB}$ are important strategies to prevent the emergence of MDR-TB [3]. Recently, reports of $\mathrm{M}$. tuberculosis strains with extensively drug resistant-TB (XDR-TB), that is MDR-TB strains with resistance to at least three of the six classes of second-line drugs, have been described $[3,4]$. The global increase in drug resistance, particularly MDR$\mathrm{TB}$, reflects, at least in part, inappropriate use of antiTB drugs during the treatment course of TB patients with drug susceptible strains [2,5]. Additional factors such as immigration, age, sex, human immunodeficiency virus (HIV) infection, and socioeconomic factors have been shown to be associated with the increased prevalence of MDR-TB [6]. The World Health Organization (WHO) has documented that MDR-TB is becoming extensively widespread today. According to the most recent data, in 2008, among all incident TB cases worldwide, 3.6\% were estimated to have MDR-TB. Almost half of the global MDR-TB cases were reported from China and India [7].

In Iran, anti-TB drug resistance rates have been reported [8,9]; however, their associated risk factors have not been fully investigated [10]. To develop a 
reasonable health-care strategy, particularly for difficult problems such as MDR-TB, current knowledge of drug resistant TB in Iran is important.

The objectives of this study were to determine first-line anti-TB drug resistance rates in new and previously treated cases at the National Reference Tuberculosis Laboratory and Lung Disease (NRITLD) of Iran. The investigation also aimed to identify certain risk factors associated with MDR-TB.

\section{Methodology}

Setting

The Iranian National Research Institute of Tuberculosis and Lung Disease (NRITLD), Masih Daneshvari Hospital, the WHO Collaborating Centre for the Middle East, is the only laboratory for Drug Susceptibility Testing (DST) of culture-positive TB specimens in the country. The NRITLD is under the technical supervision of the Supranational Reference Laboratories of the Swedish Institute (Solna, Sweden) for DST quality assurance.

\section{Study design and patients}

We reviewed retrospectively the case notes of all patients referred to our unit between December 2000 and June 2005. The inclusion criteria were all patients diagnosed with active TB with positive culture for $\mathrm{M}$. tuberculosis complex who were tested for susceptibility to first-line anti-TB drugs. Thereafter, the patients were classified into two groups: MDR-TB and non-MDR-TB.

\section{Drug susceptibility testing (DST)}

Mycobacterial species identification was performed by conventional biochemical tests [11]. All isolates were identified as M. tuberculosis complex by production of niacin, catalase activity, nitrate reduction, pigment production and growth rate. DST was routinely performed by proportion methods on Lowenstein-Jensen (LJ) medium on isolates of $\mathrm{M}$. tuberculosis. The following drug concentrations were used: INH $(0.2 \mu \mathrm{g} / \mathrm{ml})$, RMP $(40.0 \mu \mathrm{g} / \mathrm{ml})$, streptomycin "STM" $(4.0 \mu \mathrm{g} / \mathrm{ml})$, and ethambutol "EMB" $(2.0 \mu \mathrm{g} / \mathrm{ml})$. Susceptibility to pyrazinamide "PZA" (900 and $1200 \mu \mathrm{g} / \mathrm{ml}$ ) was tested using a twophase medium and if at the twenty-first reading the proportion of resistant colonies was higher than the critical proportion, the strain was reported as resistant to PZA.

\section{Definitions}

Any drug resistance was defined as resistance to one or more first-line drugs. Monoresistance was defined as resistance to only one of the five first-line drugs (INH, RMP, STM, EMB, and PZA). MDR-TB was defined as $M$. tuberculosis strains that were resistant to at least INH and RMP. Primary or initial resistance, (resistance among new cases), was defined as patients with TB resistant to one or more anti-TB drugs, but who had never been previously treated for TB. Secondary resistance, (resistance among previously treated cases), was defined as patients diagnosed with TB who started anti-TB treatment and subsequently acquired resistance to one or more of the drugs used during the treatment [12].

\section{Statistical analysis}

The results obtained were analyzed by entering the data in a binary format as a Microsoft Excel spreadsheet. Categorical data (MDR-TB and nonMDR-TB) were compared by X2 test or other variables by the Fisher's exact test. A $p$ value of less than 0.05 was considered statistically significant.

\section{Ethics approval}

The study was approved by the ethics committee of NRITLD in Tehran.

\section{Results}

Patients

Between December 2000 and June 2005 a total of 1,742 TB patients were included in the study. Of these, $1,139(65.4 \%)$ were new cases and $603(34.6 \%)$ were previously treated cases. The mean age of patients was $44.2 \pm 17.4 \mathrm{yr}(\mathrm{SD})$, and $935(53.7 \%)$ were male and $807(46.3 \%)$ were female. A total of $1,074(61.7 \%)$ were native Iranians and 668 (38.3\%) were Afghan immigrants (Afghan) patients. The characteristics of this population are summarized in Table 1 .

\section{Drug resistance of $M$. tuberculosis}

Of the 1,742 patients with M. Tuberculosis, 986 $(56.6 \%)$ had TB that was susceptible to all drugs, and $756(43.4 \%)$ were resistant to at least one antimicrobial drug. With regard to at least one drug resistance, the resistance rates of $\mathrm{M}$. tuberculosis to the tested first-line drugs were as follows: INH (414, $23.8 \%)$, RMP (307, 17.6\%), PZA (165, 9.5\%), EMB $(207,11.9 \%)$, and STM $(478,27.4 \%)$.

The results of the sensitivity tests in the patients with TB were classified according to the history of treatment (new versus previously treated cases), are shown in Table 2. Out of the 1,139 new cases, $799 \mathrm{M}$. 
Table 1. Characteristics of the study population $($ no $=1742)$

\begin{tabular}{|l|l|c|}
\hline & Variable & no (\%) \\
\hline \multirow{2}{*}{ Age } & Mean age & $44.2 \pm 17.4$ \\
\hline \multirow{2}{*}{ Gender } & Male & $935(53.7)$ \\
\cline { 2 - 3 } & Female & $807(46.3)$ \\
\hline \multirow{2}{*}{ Type of patient } & New case & $1139(65.4)$ \\
\cline { 2 - 3 } & Previous TB treatment & $603(34.6)$ \\
\hline \multirow{2}{*}{ Region of origin } & Iranian & $1074(61.7)$ \\
\cline { 2 - 3 } & Immigrant (Afghans) & $668(38.3)$ \\
\hline \multirow{2}{*}{ Socio-economic factors } & Pulmonary & $1615(92.7)$ \\
\cline { 2 - 3 } & Extra-pulmonary & $127(7.3)$ \\
\hline
\end{tabular}

Table 2. First line anti-tuberculosis drugs resistance in M. tuberculosis strains (new vs previously treated cases)

\begin{tabular}{|c|c|c|c|}
\hline DST & $\begin{array}{c}\text { New Cases } \\
(\text { no }=1139) \\
\text { no }(\%)\end{array}$ & $\begin{array}{l}\text { Previously treated cases } \\
(\text { no }=603) \\
\text { no }(\%)\end{array}$ & $\begin{array}{c}\text { Total DST } \\
(\text { no }=1742) \\
\text { no }(\%)\end{array}$ \\
\hline Pan-susceptible & 799 (70.1) & $187(31.0)$ & $986(56.6)$ \\
\hline Any drug resistance & 340 (29.9) & $416(69.0)$ & $756(43.4)$ \\
\hline INH & $141(12.4)$ & $273(45.3)$ & $414(23.8)$ \\
\hline RMP & $89(7.8)$ & $218(36.2)$ & $307(17.6)$ \\
\hline PZA & $18(1.6)$ & $147(24.4)$ & $165(9.5)$ \\
\hline EMB & $24(2.1)$ & $183(30.3)$ & $207(11.9)$ \\
\hline STM & $233(20.5)$ & $245(40.6)$ & $478(27.4)$ \\
\hline Monoresistance & $222(19.5)$ & $157(26.0)$ & $379(21.8)$ \\
\hline INH & $30(2.6)$ & $22(3.6)$ & $52(3.0)$ \\
\hline RMP & $10(0.9)$ & $19(3.2)$ & $29(1.7)$ \\
\hline PZA & $4(0.4)$ & $6(1.0)$ & $10(0.6)$ \\
\hline EMB & $8(0.7)$ & $22(3.6)$ & $30(1.7)$ \\
\hline STM & $170(14.9)$ & $88(14.6)$ & $258(14.8)$ \\
\hline 2 drugs & $41(3.6)$ & $49(8.1)$ & $90(5.2)$ \\
\hline$>2$ drugs & $5(0.4)$ & $19(3.2)$ & 24 (1.4) \\
\hline MDR-TB & $72(6.3)$ & $191(31.7)$ & $263(15.1)$ \\
\hline
\end{tabular}


Table 3. Univariate analysis of association of risk factors with MDR-TB

\begin{tabular}{|c|c|c|c|c|c|}
\hline \multicolumn{2}{|l|}{ Variable } & $\begin{array}{c}\begin{array}{c}\text { Non-MDR-TB } \\
(\text { no }=1479) \\
\text { no }(\%)\end{array} \\
\end{array}$ & $\begin{array}{c}\text { MDR-TB } \\
(\text { no }=263) \\
\text { no }(\%) \\
\end{array}$ & $\begin{array}{l}\text { Odd ratio } \\
(95 \% \text { CI) }\end{array}$ & P-Value \\
\hline \multirow{2}{*}{ Age } & Age $<45$ yr & $888(60.0)$ & $185(70.3)$ & \multirow{2}{*}{$1.57(1.18-2.09)$} & \multirow{2}{*}{0.002} \\
\hline & Age $>45 \mathrm{yr}$ & $591(40.0)$ & $78(29.7)$ & & \\
\hline \multirow{2}{*}{ Gender } & Male & $751(50.8)$ & $184(70.0)$ & \multirow{2}{*}{$2.25(1.70-2.99)$} & \multirow{2}{*}{0.000} \\
\hline & Female & $728(49.2)$ & $79(30.0)$ & & \\
\hline \multirow{2}{*}{$\begin{array}{l}\text { Type of } \\
\text { patient }\end{array}$} & New Case & $1067(72.1)$ & $72(27.4)$ & \multirow{2}{*}{$6.87(5.12-9.21)$} & \multirow{2}{*}{0.000} \\
\hline & Previous TB treatment & $412(27.9)$ & $191(72.6)$ & & \\
\hline \multirow{2}{*}{$\begin{array}{l}\text { Region of } \\
\text { origin }\end{array}$} & Iranian & $986(66.7)$ & $88(33.5)$ & \multirow{2}{*}{$3.97(3.01-5.24)$} & \multirow{2}{*}{0.000} \\
\hline & Immigrant (Afghans) & $493(33.3)$ & $175(66.5)$ & & \\
\hline \multirow{2}{*}{$\begin{array}{l}\text { Site of } \\
\text { disease }\end{array}$} & Pulmonary & $1375(93.7)$ & $240(91.3)$ & \multirow{2}{*}{$1.16(0.72-1.85)$} & \multirow{2}{*}{0.5} \\
\hline & Extra-pulmonary & $104(7.0)$ & $23(8.7)$ & & \\
\hline \multirow{2}{*}{$\begin{array}{l}\text { Socio- } \\
\text { economic } \\
\text { factor }\end{array}$} & Poor living condition & $1180(79.8)$ & $196(74.5)$ & $0.56(0.41-0.77)$ & 0.002 \\
\hline & Un-employment & $756(51.1)$ & $112(42.6)$ & $0.70(0.54-0.92)$ & 0.01 \\
\hline
\end{tabular}

Table 4. Multivariate analysis of risk factors associated with MDR-TB

\begin{tabular}{|c|c|c|c|}
\hline \multicolumn{2}{|l|}{ Variable } & $\begin{array}{c}\text { a Odd ratio } \\
(95 \% \mathrm{CI})\end{array}$ & P-Value \\
\hline \multirow{2}{*}{ Age } & Age $<45$ yr & \multirow{2}{*}{$1.41(1.02-1.93)$} & \multirow{2}{*}{0.01} \\
\hline & Age $>45 \mathrm{yr}$ & & \\
\hline \multirow{2}{*}{ Gender } & Male & \multirow{2}{*}{$1.83(1.28-2.57)$} & \multirow{2}{*}{0.002} \\
\hline & Female & & \\
\hline \multirow{2}{*}{ Type of patient } & New Case & \multirow{2}{*}{$4.43(2.68-4.77$} & \multirow{2}{*}{0.001} \\
\hline & Previous TB treatment & & \\
\hline \multirow{2}{*}{ Region of origin } & Iranian & \multirow{2}{*}{$2.52(1.56-3.79)$} & \multirow{2}{*}{0.004} \\
\hline & Immigrant (Afghans) & & \\
\hline
\end{tabular}


tuberculosis isolates $(70.1 \%)$ were susceptible to all first-line drugs, while 187 isolates $(31.0 \%)$ of the 603 previously treated cases were susceptible to all firstline drugs. Furthermore, 141 new cases and 274 previously treated cases were resistant to INH $(12.4 \%$ and $45.3 \%$, respectively). Seventy-two cases of MDRTB were observed among new cases $(6.3 \%)$, and 191 among previously treated cases $(31.7 \%)$. (Table 2$)$

\section{Trends in anti-TB drug resistance}

Figure 1 shows the proportion of TB cases with MDR-TB and other resistance patterns by year. From 2001 to 2005 the percentage of MDR-TB and other resistance patterns remained almost stable with a slight decrease.

\section{Risk factors associated with MDR-TB patients}

Based on DST, the patients were divided into two groups: 1,479 patients were non-MDR and 263 patients were MDR-TB. Table 3 shows the number of MDR-TB patients for each of the variables analyzed and the crude odds ratios for MDR-TB. The only variables significantly associated with MDR were under 45 years of age, male sex, previous treatment, immigrants (Afghans), poor living conditions, and unemployment

Based on the univariate logistic regression analysis, patients with MDR-TB were more likely to be under 45 years of age $(70.3 \%)$ and male $(70.0 \%)$ than non-MDR-TB patients $(60.0 \%, \mathrm{p}=0.002$ and $50.8 \%, \mathrm{p}<0.05$, respectively). MDR-TB cases $(72.6 \%)$ were also more likely to have received previous treatment than non-MDR-TB $(27.9 \%)$ cases $(\mathrm{p}<0.05)$. Afghan immigrant patients $(66.5 \%)$ were more likely to have MDR than non-MDR-TB (33.3\%) $(\mathrm{p}<0.05)$. In addition, patients with MDR-TB were likely to have had poor living conditions $(74.5 \%)$ and to be unemployed $(42.6 \%)$ in comparison to patients with non-MDR-TB $(79.8 \%$ and $51.1 \%, p=0.002$ and $\mathrm{p}=0.01$, respectively) (Table 3 ). All variables that according to univariate analysis were related to MDR$\mathrm{TB}$ at a $\mathrm{p}$ value less than 0.05 were included in the multivariate logistic regression model for real effects of variables. According to multivariate analysis, the following factors were significantly related to MDRTB: age younger than 45 years, male sex, previous TB treatment, and immigration (Table 4).

\section{Discussion}

Information on anti-TB drug resistance patterns, particularly among new and previously treated cases, is crucial for planning an effective MDR-TB control programme. The objectives of this retrospective study, which included all TB patients a for 4.5-year period, were to identify first-line anti-TB drug resistance in new and previously treated cases and to determine risk factors associated with MDR-TB at the National Reference Tuberculosis Laboratory in Iran.

In the present study, we found that drug resistance to STM $(478,27.4 \%)$ was the most common, followed by INH $(414,23.8 \%)$. This is in agreement with the observations of other Iranian researchers $[7,8,13]$. The high prevalence of STM resistance in our study may be due to widespread use of STM in the past for

Figure 1. Anti-TB resistance trends 2001 - Jun 2005

\section{Multidrug drug resistant pattern $\quad$ Other resistance pattern}

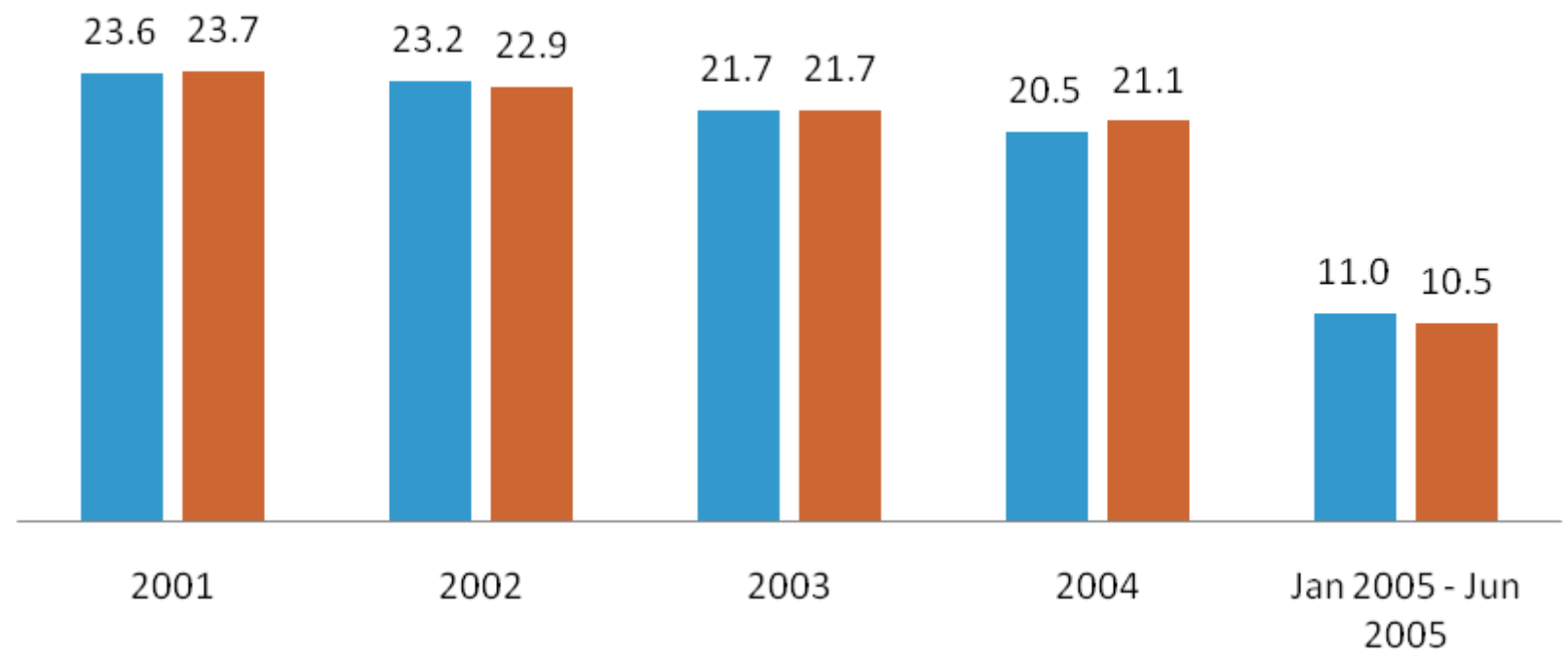


Figure 2. Anti-TB drug resistance pattern reported in current and previous studies in Iran

= Current study (2000-2005)

= Mirsaeidi el al. (2003-2004)

= Shamaei et al. (2000-2003)

- Mansoori et al. (1996-2000)

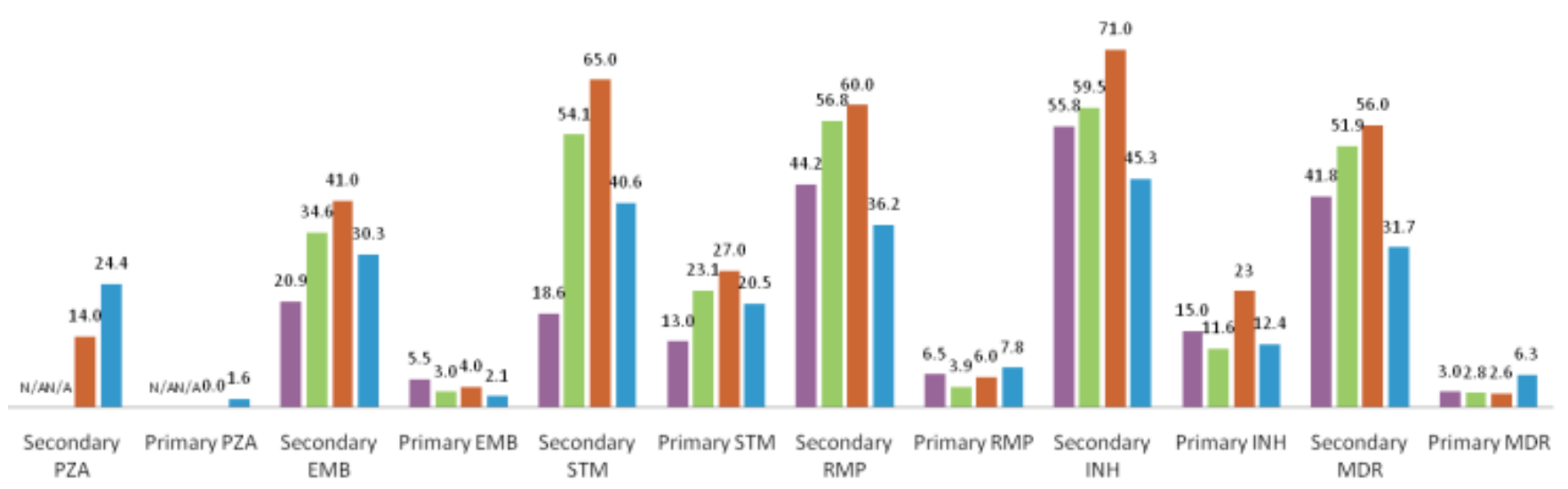

treatment of different infectious diseases. Furthermore, its high resistance rate guides the decision maker to limit STM use in the TB treatment regimen for susceptible and MDR-TB strains. Hence EMB is recommended. In this study, we found that the rate of any drug resistance and MDR-TB was 756 (43.4\%) and $263(15.1 \%)$, respectively. The rate is high compared to figures from some studies in the region [14-16]. The estimated primary and acquired resistance to any drugs $(29.9 \%$, and $69.0 \%$, respectively) were similar to the results of previous studies in Iran with minor differences in the precise proportions for resistance to specific first-line anti-TB drugs $[9,13,17]$ (Figure 2).

The estimated proportion of MDR-TB (4.1\%) compared with that for secondary MDR-TB (11\%) in our study is higher than that shown in the earlier reports $[9,13,17]$ in the same centre. The discrepancy in findings between the present study and those of previous studies can be explained by the differences in the nature of the populations included in the different studies. The previous studies were conducted on hospitalized TB patients with a considerable proportion of treatment failures and relapses at the National Research Institute of Tuberculosis and Lung Diseases (NRITLD). The present study, which was conducted at NRITLD, included patients both hospitalized in the same centre and those referred from other hospitals and health centres for investigation and reporting. Based on the MDR-TB findings, therefore, the rate of prevalence of acquired MDR-TB was five times higher than that of primary MDR-TB in this study. The WHO and International Union Against Tuberculosis and Lung Disease (IUATLD) working group on global surveillance for anti-TB drug resistance reported a prevalence of primary MDR of $1.4 \%$, and acquired resistance of $13 \%$ in previously treated cases [18]. Thus prevalence of MDR-TB is 10 times higher in previously treated cases.

The high prevalence of initial MDR-TB in our study is assumed to be due to recent transmission of drug resistant strains. Overall, the rate of drug resistance in our study was high, which is in line with findings of some high-burden countries. $\mathrm{He}$ et al. reported the prevalence of any drug resistance in 10 provinces of China as $24.3 \%$ (range $14.8 \%-42.1 \%$ ) among new cases and $51.8 \%$ (range $27.5 \%-67.5 \%$ ) among previously treated cases. In contrast, the prevalence of MDR-TB was $5.4 \%$ (range $2.1 \%$ $10.4 \%$ ) among new cases and $25.6 \%$ (range $11.7 \%-$ $36.9 \%$ ) among previously treated cases [19]. In comparison to our study, lower MDR-TB rates, specifically $2 \%$ for new cases and $29.4 \%$ for previously treated cases, were reported from the WHO Eastern Mediterranean Region [20]. Strikingly, the high MDR-TB rate in this study is a matter of great concern and may indicate increasing trends of MDRTB. Therefore, a community-based study is recommended to gain a better understanding of the trends of drug resistance within the country. The antiTB drug resistance trends are presented in a longitudinal graph, which shows no significant trends by year (Figure 1).

In this study, univariate analysis showed six relevant risk factors of MDR-TB. Age under 45 years, 
Table 5. Significant risk factors associated with MDR-TB reported in current and previous studies in Iran

\begin{tabular}{|c|c|c|c|c|c|}
\hline Reference & Time/place & Design & $\begin{array}{l}\text { Population } \\
\text { studies No. }\end{array}$ & $\begin{array}{c}\text { No. of MDR- } \\
\text { TB }\end{array}$ & Factor \\
\hline Current study & $\begin{array}{l}\text { Dec } 2000 \text { - Jun } 2005 \\
\text { NRL, NRITLD }\end{array}$ & $\begin{array}{l}\text { Retrospective } \\
\text { laboratory notes } \\
\text { based study }\end{array}$ & 1742 & 263 & $\begin{array}{c}\text { Age }<45 \\
\text { Male sex } \\
\text { Previous treatment } \\
\text { Immigrant (Afghan) } \\
\text { Poor living conditions } \\
\text { Un-employment }\end{array}$ \\
\hline Shamaei et al. & $\begin{array}{c}\text { Mar } 2000 \text { - Feb 2003, } \\
\text { TB department, } \\
\text { NRITLD }\end{array}$ & $\begin{array}{c}\text { Retrospective } \\
\text { hospital notes based } \\
\text { study }\end{array}$ & 548 & 106 & $\begin{array}{c}\text { Age }>65 \\
\text { Immigrant (Afghan) } \\
\text { Previous treatment }\end{array}$ \\
\hline Mirsaeidi et al. & $\begin{array}{c}\text { Jun } 2003 \text { to Sep } 2004, \\
\text { TB department, } \\
\text { NRITLD }\end{array}$ & $\begin{array}{l}\text { Anterograde patient } \\
\text { interview study }\end{array}$ & 264 & 45 & Previous treatment \\
\hline Baghaei et al. & $\begin{array}{c}2002 \text { - 2005, TB } \\
\text { department, NRITLD }\end{array}$ & $\begin{array}{c}\text { Retrospective } \\
\text { hospital based } \\
\text { study } \\
\end{array}$ & 282 & 48 & $\begin{array}{c}\text { Previous treatment } \\
\text { Immigrant (Afghan) } \\
\text { Positive sputum smear }\end{array}$ \\
\hline
\end{tabular}

male sex, previous TB treatment, immigration, poor living conditions, and unemployment were independent risk factors for MDR-TB. To address possible cofounders in the present study, all variables analyzed in the univariate analysis were included in the multivariate logistic regression method. After the analysis, four variables remained in the multivariate model, namely age under 45 years, male sex, previous TB treatment, and immigration. These figures are nearly consistent with findings from previous studies $[9,10,13]$ in the same institute with the exception of the age (Table 5).

In contrast to our findings, Shamaei et al. [9] reported that age older than 65 years was significantly associated with MDR-TB. However, in a study done by Baghaei et al. in the same centre, the mean age of MDR-TB patients was $43.51+18.4 \mathrm{yrs}$, but the finding was not statistically significant [10]. In the present study, the association of MDR strains with a young age group might be explained by the inclusion of a larger sample size from the whole country. Several reports found that younger age and male gender were predominantly associated with drug resistance TB [14,21,22]. A review by Faustini et al. [6] reported that MDR-TB was more common in patients under 65 years of age, but the association was weak and more heterogeneous in patients under 45 years. The high frequency of drug resistance among a young age group in the present study may indicate the occurrence of recent transmission, whereas in the older age group, the infection has been acquired in the past.
Therefore, careful monitoring of transmission trends of drug resistant strains should be considered a priority to ensure a successful TB control programme. This should be done through increased awareness, early case detection, rapid drug susceptibility testing, a full course of effective anti-TB treatment, continuous community-based surveillance of anti-TB drug resistance, and control of drug resistant $\mathrm{TB}$ at the border entry points with neighboring TB high-burden countries.

The higher prevalence of MDR-TB in men over women may be explained by the fact that women are more compliant with treatment and therefore less likely to receive inadequate treatment than men. Furthermore, men are almost always outdoors and therefore more susceptible to community-acquired resistant strains.

Previous treatment has been well documented to be associated with MDR-TB in many studies $[5,9,10,13,16,21,23,24]$. It may potentiate drug resistance through improper drug regimens, inadequate or irregular drug supply, unsatisfactory compliance by patients or clinicians, lack of supervision of treatment, and absence of infection control measures in hospitals. Immigration has been suggested as one factor leading to increased prevalence of MDR-TB in many countries $[2,6,9,10]$. In our study, a possible explanation for the high rate of MDR-TB in Afghan cases may be the poorer access to health-care facilities and higher risk of transmission of MDR strains for immigrants. It has been shown that Afghan immigrants play an important 
role in maintaining recurrent tuberculosis. Our previous study at the same NRITLD showed that the intra-community transmissions between Iranian and Afghan patients were $41 \%$. It has also been shown that more than $90 \%$ of active cases of TB in Iran resulted from reactivation of infection, and that recently transmitted diseases had a minor role. Recently, however, this picture has changed and a higher rate of reactivation $(74.8 \%)$ versus recent transmission $(25.2 \%)$ occurred in Iran [25]. Hence the proportion of endogenous versus imported TB changed over time. Therefore, further fingerprinting studies are recommended to gain a better understanding of change over time.

Our study revealed that Afghan immigrants were younger than Iranian (data not shown). This finding, which agrees with the observations in our previous study, [26] suggests that younger persons and persons who have emigrated from Afghanistan and from other TB high-burden settings may be at higher risk for transmitting MDR-TB strains. Furthermore, nomadic populations such as the Afghan immigrant patients contribute to the circulation of MDR strains, as opposed to the settled Iranian MDR-TB patients. This finding supports the proposal for a policy for screening all immigrants to Iran for TB, especially those from TB high-burden countries. The new strategy of the Iranian National TB Programme (NTP) is to screen all immigrants at border entry points from countries with high levels of drug resistance such as Afghanistan, Pakistan, and Azerbaijan. Positive patients would be subjected to anti-TB treatment before being allowed into the country.

The study's main limitation is that we could not include other important variables associated with MDR-TB such as HIV infection, diabetes mellitus, cavitary chest lesion, and drug abuse, as sufficient information on these parameters were missing in the case notes. Furthermore, the different sample sizes and the different time periods of different Iranian studies reduce the validity of the comparative findings.

In conclusion, this study reflects the rising trend of resistance in the community. DST is routinely recommended to provide optimal treatment to culture positive TB cases with high risk of drug resistance, especially in immigrants from TB high-burden countries. The high rate of initial resistance in MDRTB cases and the high rate of MDR-TB among a young age group were indicators of recent transmission, which suggests potential trends. Therefore, closer monitoring of transmission trends of drug resistant strains should be considered as priority, to ensure a successful TB control programme. This should be done through increased awareness, early case detection, rapid drug susceptibility testing, a full course of effective anti-TB treatment, continuous surveillance of anti-TB drug resistance, and control of drug resistant $\mathrm{TB}$ at border entry points with neighboring TB-high burden countries.

\section{Acknowledgments}

We would like to thank all the staff at the Mycobacteriology Research Centre (MRC) - National Research Institute of Tuberculosis and Lung Diseases (NRITLD), Tehran, Iran, for their considerable help and support in this work. The study was supported by National Research Institute of Tuberculosis and Lung Disease-Tehran-Iran.

\section{References}

1. World Health Organization 2009 Global Tuberculosis Control: Epidemiology, Strategy, Financing: WHO report 2009. WHO/HTM/TB/2009.411. Geneva, Switzerland: WHO, 2009.

2. Espinal MA, Laszlo A, Simonsen L, Boulahbal F, Kim SJ, Reniero A, Hoffner S, Rieder HL, Binkin N, Dye C, Williams R, Raviglione MC (2001) Global Trends in Resistance to Antituberculosis Drugs. N Engl J Med 344: 1294-1303.

3. Masjedi MR, Farnia P, Sorooch S, Pooramiri MV, Mansoori SD, Zarifi AZ, Velayati AA, Hoffner S (2006) Extensively drug resistant tuberculosis: 2 years of surveillance in Iran. Clin Infect Dis 43: 840-847.

4. Blaas SH, Mütterlein R, Weig J, Neher A, Salzberger B, Lehn N, Naumann L (2008) Extensively drug resistant tuberculosis in a high income country: a report of four unrelated cases. BMC Infect Dis 8: 60.

5. Caminero JA (2005) Management of multidrug-resistant tuberculosis and patients in retreatment. Eur Respir J 25: 928936.

6. Faustini A, Hall AJ, Perucci CA (2006) Risk factors for multidrug resistant tuberculosis in Europe: a systematic review. Thorax 61: 158-163.

7. World Health Organization 2010 Multidrug and extensively drug-resistant TB (M/XDR-TB). 2010 Global Report on Surveillance and Response. WHO/HTM/TB/2010.3. Geneva, Switzerland: WHO, 2010.

8. Ramazanzadeh R, Farnia P, Amirmozafari N, Ghazi F, Ghadertotonchi Z, Kamran J, Mohammadi F, Mirsaedi M, Masjedi M (2006) Comparison between Molecular Epidemiology, Geographical Regions and Drug Resistance in Mycobacterium tuberculosis Strains Isolated from Iranian and Afghan Patients. Chemotherapy 52: 316-320.

9. Shamaei M, Marjani M, Chitsaz E, Kazempour M, Esmaeili M, Farnia P, Tabarsi P, Amiri MV, Mirsaeidi M, Mansouri D, Masjedi MR, Velayati AA (2009) First-line anti-tuberculosis drug resistance patterns and trends at the national TB referral center in Iran--eight years of surveillance. Int J Infect Dis 13: e236-240.

10. Baghaei P, Tabarsi P, Chitsaz E, Novin A, Alipanah N, Kazempour M, Mansouri D (2009) Risk Factors Associated with Multidrug-Resistant Tuberculosis. Tanaffos 8: 17-21.

11. Kent PT, Kubica GP (1985). Public Health Mycobacteriology: A guide for level II laboratory. Atlanta, 
GA. Public Health Services, US Department of Health and Human Services.

12. World Health Organization 2009 Guidelines for surveillance of drug resistance in tuberculosis-4th ed. WHO/HTM/TB/2009.422. Geneva, Switzerland: WHO, 2009.

13. Mirsaeidi MS, Tabarsi P, Farnia P, Ebrahimi G, Morris MW, Masjedi MR, Velayati AA, Mansouri D (2007) Trends of drug resistant Mycobacterium tuberculosis in a tertiary tuberculosis center in Iran. Saudi Med J 28: 544-550.

14. Surucuoglu S, Ozkutuk N, Celik P, Gazi H, Dinc G, Kurutepe S, Koroglu G, Havlucu Y, Tuncay G (2005) Drug-resistant pulmonary tuberculosis in western Turkey: prevalence, clinical characteristics and treatment outcome. Ann Saudi Med 25: 313-318.

15. Al-Orainey IO, Saeed ES, El-Kassimi EA, Al-Shareef A (1989) Resistance to antituberculosis drugs in Riyadh, Saudi Arabia. Tubercle 70: 207-210.

16. Antunes ML, Aleixo-Dias J, Antunes AF, Pereira MF, Raymundo E, Rodrigues MF (2000) Anti-tuberculosis drug resistance in Portugal. Int J Tuberc Lung Dis 4: 223-231.

17. Mansoori SD, Arami S, Mirabolhasani Z, Farnia P, Velayati AA (2003) Pattern of drug resistance among newly diagnosed and old cases of pulmonary tuberculosis in NRITLD. Arch Iranian Med 6: 255-260.

18. Pablos-Mendez A, Raviglione MC, Laszlo A, Binkin N, Rieder HL, Bustreo F, Cohn DL, Lambretgts-van Weezenbeek CSB, Kin SJ, Chaulet P, Nunn P (1998) Global surveillance for antituberculosis-drug resistance, 1994-1997. N Engl J Med 338: 1641-1649.

19. He GX, Zhao YL, Jiang GL, Liu YH, Xia H, Wang SF, Wang LX, Borgdorff MW, van der Werf MJ, van den Hof S (2008) Prevalence of tuberculosis drug resistance in 10 provinces of China. BMC Infect Dis 8: 166.

20. Zignol M, Hosseini MS, Wright A, van Weezenbeek CL, Nunn P, Watt CJ, Williams BG, Dye C (2006) Global incidence of multidrug-resistant tuberculosis. J. Infect. Dis 194: 479-485.

21. García-García ML, Ponce de León A, Jiménez-Corona ME, Jiménez-Corona A, Palacios-Martínez M, BalandranoCampos S, Ferreyra-Reyes L, Juárez-Sandino L, SifuentesOsornio J, Olivera-Díaz H, Valdespino-Gómez JL, Small PM (2000) Clinical consequences and transmissibility of drug- resistant tuberculosis in southern Mexico. Arch Intern Med 160: 630-636.

22. Granich RM, Oh P, Lewis B, Porco TC, Flood J (2005) Multidrug resistance among persons with tuberculosis in California, 1994-2003. JAMA 293: 2732-2739.

23. Ruddy M, Balabanova Y, Graham C, Fedorin I, Malomanova N, Elisarova E, Kuznetznov S, Gusarova G, Zakharova S, Melentyev A, Krukova E, Golishevskaya V, Erokhin V, Dorozhkova I, Drobniewski F (2005) Rates of drug resistance and risk factor analysis in civilian and prison patients with tuberculosis in Samara Region, Russia. Thorax 60: 130-135.

24. Suárez-García I, Rodríguez-Blanco A, Vidal-Pérez JL, García-Viejo MA, Jaras-Hernández MJ, López O, Noguerado-Asensio A (2009) Risk factors for multidrugresistant tuberculosis in a tuberculosis unit in Madrid, Spain. Eur J Clin Microbiol Infect Dis 28: 325-330.

25. Farnia P, Masjedi MR, Varahram M, Mirsaeidi M, Ahmadi M, Khazampour M, Tabarsi $P$, Baghei $P$, Marjane $M$, Bahadori M, Zarifi AZ, Velayati AA (2008). The RecentTransmission of Mycobacterium tuberculosis Strains among Iranian and Afghan Relapse Cases: a DNA-fingerprinting using RFLP and spoligotyping. BMC Infect Dis 8: 109.

26. Farnia P, Masjedi MR, Mirsaeidi M, Mohammadi F, Ghanavi J, Vincent V, Bahadori M, Velayati AK (2006) Prevalence of Haarlem I and Beijing Types of Mycobacterium tuberculosis strains in Iranian and Afghan MDR-TB patients. J Infect 53: $331-336$

\section{Corresponding author}

Muayad A. Merza

MRC, NRITLD

Shahid Beheshti University (Medical Campus)

Shaheed Bahonar Avenue, Darabad

PO Box 19575/154

Tehran 19556, Iran

Tel.: +98 218408275 Fax: +98 212285777 .

Email: muayadfaily@yahoo.com

Conflict of interests: No conflict of interests is declared. 